\title{
Texture and mineralogy influence on durability: the Macigno sandstone
}

\author{
Simona Scrivano ${ }^{\text {* }}$, Laura Gaggero ${ }^{1}$, Josep Gisbert Aguilar ${ }^{2}$, Tim de Kock ${ }^{3}$, \\ Hannelore Derluyn ${ }^{3,4} \&$ Veerle Cnudde ${ }^{3}$ \\ ${ }^{1}$ Department of Earth, Environment and Life Sciences, University of Genoa, Italy \\ ${ }^{2}$ Department of Earth Sciences, University of Zaragoza, Spain \\ ${ }^{3}$ UGCT - PProGRess, Department of Geology, Ghent University, Belgium \\ ${ }^{4}$ CNRS/TOTAL/Université Pau \& Pays Adour, Laboratoire des fluides complexes et leurs réservoirs-IPRA, UMR5150, \\ 64000, Pau, France \\ (1) S.S., 0000-0002-1205-8563; L.G., 0000-0002-7912-6671; J.G.A., 0000-0002-3276-5871; H.D., 0000-0002-1574-1456 \\ *Correspondence: simona.scrivano@edu.unige.it
}

\begin{abstract}
The behaviour of ornamental stones in response to environmental changes or interactions is crucial when dealing with the conservation of cultural heritage. Weathering factors affect each rock differently, depending on structure, mineralogy, and extraction and implementation techniques. This work focuses on the Macigno sandstone, a dimension stone often employed in Tuscany over the centuries. A thorough mineralogical (optical microscopy, scanning electron microscopy and X-ray powder diffraction) and petrophysical characterization (i.e. mercury intrusion porosimetry, X-ray computed tomography, hygroscopic adsorption behaviour, ultrasounds, image analysis and capillary uptake) was made of the sandstone type extracted in the area of Greve in Chianti. The lithotype shows mineralogical (i.e. presence of mixed-layer phyllosilicates) and microporosimetric features, leading to a high susceptibility to relative humidity variation. Moreover, the influence of swelling minerals is related to weathering due to saline solution. The joint application of petrographic and petrophysical techniques allows an understanding of the characteristic weathering pattern of exfoliation (i.e. detachment of multiple thin stone layers, centimetre scale, that are sub-parallel to the stone surface).
\end{abstract}

Received 29 October 2016; revised 11 April 2017; accepted 11 May 2017

The Macigno sandstone (EN 12440:2000) is a dimension stone found throughout Tuscany (Italy). The easy workability and the bluish-grey colour allowed its widespread use through the centuries. Its employment dates back to the Middle Ages, when it was first adopted as a building material, before being used mainly in the Renaissance as material for architectural ornamental elements. From the nineteenth century onwards, the lithotype was adopted mainly as a paving stone. Several highly important cultural heritage monuments in Italy are made of this sandstone, for example Brunelleschi's Cupola, the Piazza della Signoria, the Ospedale degli Innocenti, the Laurenziana Library and the Uffizi Porch in Florence. This lithotype is quarried from the Macigno/Monte Modino Formation, which extends in the Ligurian Apennines southward to the Grosseto area (Fig. 1). One of the extraction sites that is still active is located in the Macigno Formation (Upper Oligocene, Tuscan Nappe Unit), on the eastern side of the large anticlinal Apennine-oriented structure forming the ridge of the Chianti hills, at Greve in Chianti, in the locality of Caprolo (Fig. 1). This formation originated in turbidity currents, resulting in alternating layers of sandstone (up to $5 \mathrm{~m}$ thick) and thin pelite levels.

Detritic quartz and feldspars, secondary calcite and phyllosilicates mainly comprise the Macigno sandstone, which presents bluish-grey fresh cut surfaces, and yellowish surfaces when weathered (Bastogi \& Fratini 2004). Falorni (2007) classified this rock as a greywacke, with matrix (clasts $<30 \mu \mathrm{m}$ ) at about $15 \mathrm{wt} \%$, thus corresponding between greywacke and arkosic arenites/ litharenite. The lithic fraction is composed mainly of metamorphic $(70-80 \%)$, igneous $(15-20 \%)$ and sedimentary (15\%) clasts, allowing identification of different depositional layers. The rare occurrences of foraminifera allowed dating of the whole formation to the Oligocene (Falorni 2007).

The mineralogical-petrographic characteristics act as an internal factor in deterioration mechanisms, influencing the predisposition of the lithotype to be susceptible to environmental changes, such as temperature or humidity changes, pollution, water, etc. (Benavente et al. 2008; Gioncada et al. 2011; Pecchioni et al. 2016). The Macigno sandstone, in spite of the good technical properties that make it suitable as a dimension stone, suffers from a typical weathering process, namely exfoliation (ICOMOS \& ISCS 2008), when exposed to outdoor conditions. Such a deterioration pattern has a higher rate and extent for large percentages of expansible clay components (Veniale et al. 2001; Sebastián et al. 2008; Ruedrich et al. 2011). The presence of corrensite and chlorite-smectite (Chl-S) mixed layers with a high swelling capability is well documented along the outcrops of the Macigno Formation (Leoni et al. 2010; Gioncada et al. 2011). These clay minerals interact with water, generating aggregation-disaggregation and swellingcontraction processes (Veniale et al. 2001) through osmotic and intra-crystalline swelling (Madsen \& Mueller Vonmoos 1989). The first process is due to water molecules that are adsorbed on to the external surface of the clay particles (i.e. diffuse double layer). In the second case, water molecules interact with the interlayer cations, expanding the spacing between layers and reaching a volume increase of up to $4-5$ times compared to that of the solid phase. In mixed layers both processes can occur, inducing deformation of the rock fabric, resulting in a reduction of its mechanical properties (Delgado Rodrigues 2001).

Considering the architectural, historical and technical bearing of this stone for Italian cultural heritage, the petrophysical and mineral 

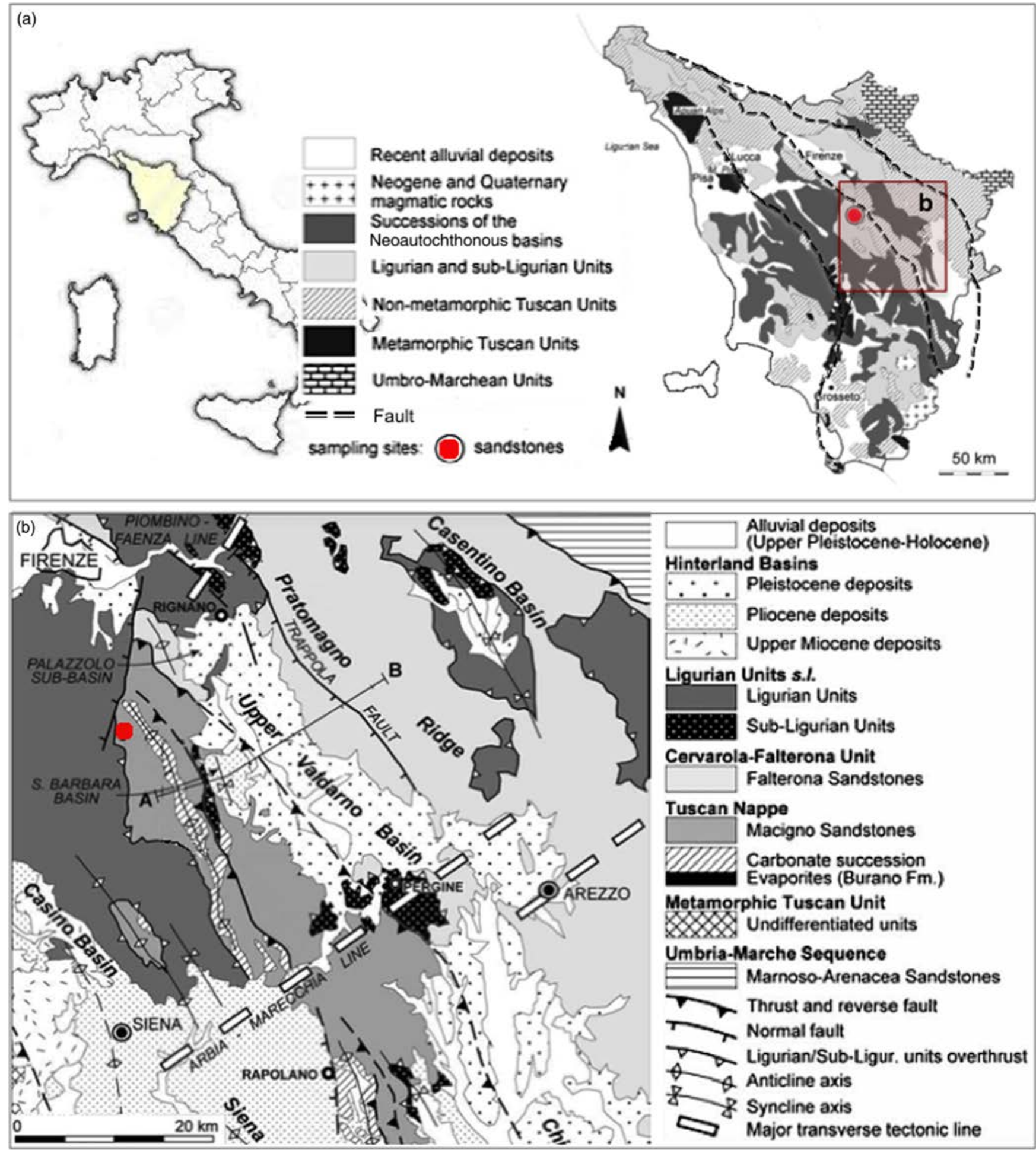

Fig. 1. (a) Geographical and geological location of the quarrying site (sketch map after Gioncada et al. 2011). (b) Geological sketch map of the Chianti Mountains-Upper Valdarno Basin and surrounding regions (adapted from Bonini et al. 2013). The large dot indicates Greve in the Chianti quarrying region.

properties were addressed, integrating high-resolution techniques for investigation of the microscale structure. Furthermore, to characterize the influence of the mineral composition and to evaluate the relevance of the rock fabric in the durability of Macigno sandstone, a set of unaltered and artificially weathered samples were compared. For reasons of clarity, the mineralogical and petrographic characterization of the Macigno sandstone and ageing test description precede the integrated petrophysical methods and related results. The consequent porosimetric characterization is aimed at unveiling the influence of anisotropy and clay content on the rock behaviour, in the presence of water.

\section{Materials}

\section{Preliminary petrographic characterization}

The sample set for analysis consisted of seven un-orientated cubic specimens $5 \times 5 \times 5 \mathrm{~cm}$, six un-orientated cubic specimens $2.5 \times$ $2.5 \times 2.5 \mathrm{~cm}$ and four mini-core specimens of freshly cut Macigno sandstone, provided by the producer from the Caprolo quarry. A detailed mineralogical petrographic study was performed on thin and polished samples, respectively, with polarized light optical microscopy (PLOM) and scanning electron microscopy (SEM). Moreover, a small amount of the samples was milled for X-ray powder diffraction 

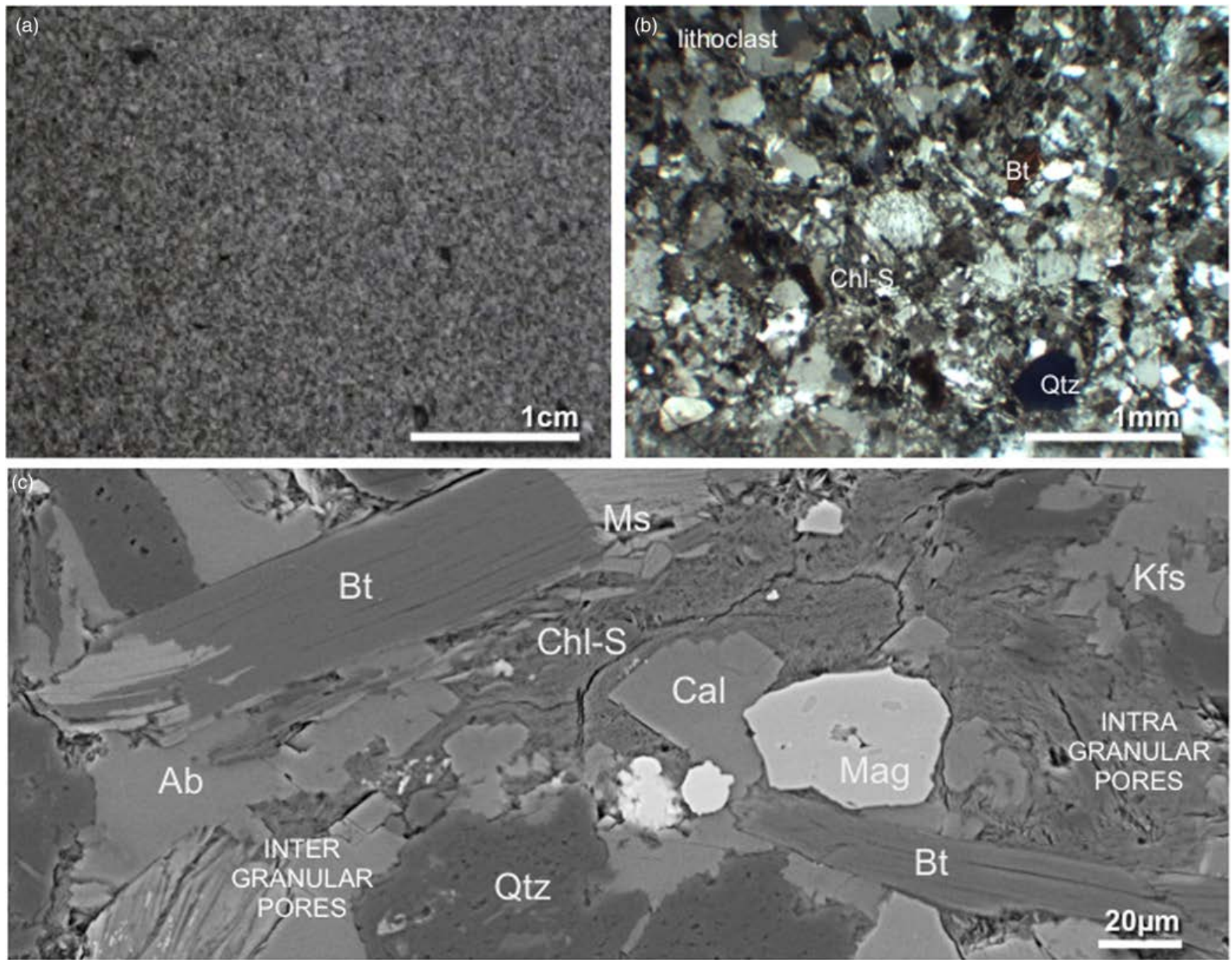

Fig. 2. Macigno sandstone. (a) Close up of the freshly cut surface. (b) Crossed polars microphotograph. The texture indicates a clast-supported sediment with very fine to medium subrounded arenite clasts. Both clast:matrix ratio and the poor sorting indicate a sub-mature lithic arkose/litharenite. (c) SEM microphotograph. Mixed Backscattered Electrons (BSE) + Secondary Electrons (SE) signal. The close up shows a net of narrow pores along grain boundaries and inside clay minerals (Chl-S), which wraps the main quartz (Qtz) and feldspar (Ab, Kfs) grains, along with the secondary mica (Bt, Ms), calcite (Cal) and magnetite (Mag) grains.

(XRPD) analysis (Fig. 2). PLOM was carried out with a petrographic microscope coupled to an Optikam B5 microscopy digital USB camera with a resolution of $2592 \times 1944$ pixels (5 Mpixels), equipped with Optika Vision Lite and Optika View acquisition software. SEM analysis was carried out using a Tescan Vega 3 LM scanning electron microscope equipped with an Apollo X detector and a Microanalysis TEAM energy dispersive system (EDS), installed at the DISTAV, University of Genoa, Italy. Microphotographs were acquired using graphitesputter-coated 3D samples under high vacuum conditions. XRPD was carried out by an automated Philips PW 1140 Xchange diffractometer. The instrument is equipped with the X'pert plus, X'pert data collector, X'pert data high score and X'pert organizer software for powder analysis of ICDD (International Center for Diffraction Data) phases. The instrument operates with a cobalt (Co) anode generating $\mathrm{X}$-rays addressed to the sample holder containing the powdered specimen. The samples were prepared grinding bulk fragments, to obtain about $0.2 \mathrm{~g}$ of powder up to $100 \mu \mathrm{m}$. The first analysis characterized the bulk specimen using a wide 2 Theta range, from 0 to 702 Theta degrees. After the first background analysis the clay mineral analysis was carried out in the range between 0 and 35 2 Theta degrees. The samples were treated in order to separate only the clay minerals from the bulk. Further ethylene glycol and thermal treatments were applied in order to discriminate clay phases affected by swelling (Milne \& Warhaw 1955).
The PLOM analyses indicated a clast-supported sediment with very fine to medium sandy clasts; sub-rounded and poorly sorted grains and grain shapes varying from spherical to elongate. The clayey cement was scarce, mixed with scarce calcite grains, and wrapped the clasts (Fig. 2). The clast:matrix ratio indicates an immature to sub-mature arenite (i.e. greywacke-lithic arkose/ litharenite). Intergranular contacts are tangential to sutured, representative of slightly compact sediment. The SEM images were collected with an optimized ratio between backscattered and secondary electrons in order to get the best signal and most complete information set. The images highlight the compositional variability and angular-sub-angular clast shapes. A network of narrow pores along grain boundaries and inside clay minerals are also visible (Fig. 2). The XRPD analysis reveals a mineral composition including quartz $\left(\mathrm{SiO}_{2}\right)$, albite $\left(\mathrm{Na}\left(\mathrm{AlSi}_{3} \mathrm{O}_{8}\right)\right)$, calcite $\left(\mathrm{Ca}\left(\mathrm{CO}_{3}\right)\right)$ and orthoclase $\left(\mathrm{Al}_{2} \mathrm{O}_{3}\left|\mathrm{~K}_{2} \mathrm{O}\right| 6 \mathrm{SiO}_{2}\right)$. The clay minerals were separated by precipitation and analysed after glycol and thermal $\left(550^{\circ} \mathrm{C}\right)$ treatment, evidencing a multi-layered mineral of the chlorite-smectite series, identified as montmorillonite-chlorite ( $\left.\mathrm{Na}-\mathrm{Ca}-\mathrm{Al}_{-}-\mathrm{Si}_{4} \mathrm{O}_{10}-\mathrm{O}\right)$.

\section{Weathering}

To evaluate the influence of internal factors on the weathering dynamic, part of the samples underwent saline contamination. The 
weathering was induced following the test procedure developed by Benavente et al. (2001). The samples were immersed for $1 / 10$ of their height in a saturated saline solution of $\mathrm{Na}_{2} \mathrm{SO}_{4}$, for 15 cycles alternating 12 hours at $40^{\circ} \mathrm{C}$ with a relative humidity $(\mathrm{RH})$ of $80 \%$ and 12 hours at $30^{\circ} \mathrm{C}$ and $60 \% \mathrm{RH}$. In order to maintain the solution concentration, the solution itself was changed every five cycles.

In order to carry out further tests on the specimens, the precipitated salts were removed with cycles of deionized water washing. The procedure was repeated until the samples stopped producing efflorescence on their surfaces while drying.

\section{Methods: Integrated approach to the investigation of intrinsic properties of the sandstone}

The following methods were applied to investigate textures and physical properties of the stone, providing a consistent dataset to unravel liability to weathering related to mineral composition.

\section{Mercury intrusion porosimetry (MIP)}

The analyses were performed at the Department of Civil, Chemical and Environmental Engineering (DICCA) of the University of Genoa (Italy) with a combined system of two porosimeters: Pascal 140 and Pascal 240. The porosimeters operate in association with the specific computer-designed software SOLID. The program allowed recasting: bulk and apparent density, porosity, average pore size, pore size distribution and particle size distribution (MayerStowe model). Each tested sample was $c .1 \mathrm{~g}$ fragment of the stone, previously dried to constant weight in the oven at $60^{\circ} \mathrm{C}$, to avoid interference with water.

\section{X-ray micro-computed tomography}

High-resolution X-ray computed tomography (HRXCT) or microCT $(\mu \mathrm{CT})$ (Cnudde \& Boone 2013) was carried out at the Ghent University Centre for X-ray Tomography (Belgium) using their custom-built instrument, the HECTOR scanner. It consists of a mechanical setup with nine motorized axes and a modular acquisition software package. It combines a micro-focus directional target X-ray source up to $240 \mathrm{kV}$ with a large flat-panel detector (Masschaele et al. 2013). A $4 \mathrm{~mm}$ mini-core sample was employed, leading to a voxel resolution of $4 \mu \mathrm{m}$. A total of 2401 projections were registered over an angle of $360^{\circ}$. A voltage of $120 \mathrm{kV}$ and a tube current around $83 \mu \mathrm{A}$ were the operating conditions. The reconstruction and $3 \mathrm{D}$ analysis of the scans was carried out with the Octopus Software (CInside Matters, Belgium) package (Vlassenbroeck et al. 2007; Brabant et al. 2011). After reconstruction of the raw data, the included algorithms allow several 3D analyses of the set of scanned images; in this work the main focus was obtaining the determination of porous and mineral fraction, and the identification, parameterization and separation of pore network.

\section{Hygroscopic adsorption}

The water adsorption properties of materials were studied following European standard EN ISO 12571:2013 with the aid of a climatic chamber, at the University of Zaragoza (Spain). The chamber was set at $21^{\circ} \mathrm{C}$ and the humidity range steps were fixed at 25,50 , 75,90 and $95 \%$. The specimens were six cubes of side length $2.5 \mathrm{~cm}$; therefore, the amount of time necessary to reach the equilibrium was limited to 24 hours. The test allowed reconstructing the sorption isotherm and the micro-porosimetric distribution of each sample.

\section{Ultrasound velocities}

Dynamic behaviour was studied by measuring the elastic longitudinal wave velocity $(\mathrm{Vp})$ with a C-370 ultrasonic tester at the University of Zaragoza, Spain. Six cubic samples, with equal sides of $5 \mathrm{~cm}$, were prepared for each lithotype, so nine measurements were made for a single test and the mean was taken as the representative value. In this study, the direct method of measuring the ultrasonic velocity was applied. The samples were dried in an oven at a constant temperature of $60^{\circ} \mathrm{C}$ for 48 hours until reaching a constant mass. The end surfaces of the samples were polished to provide good coupling with the transducers, allowing precise measurements.

\section{Image analyses}

Image analysis was carried out on images obtained with a Tescan Vega 3 LM scanning electron microscope installed at the DISTAV, University of Genoa, Italy. The samples were graphitesputtercoated polished chips of the unaltered sample, analysed under high vacuum conditions. JMicrovision software (Roduit 2007) was used to build the measure dataset from each image. The 2D image analysis provided a reconstruction of the preferential orientation of the constituent minerals (Gioncada et al. 2011), unveiling the bedding planes.

\section{Capillary absorption}

For determination of the capillary absorption (UNI EN 15801:2010), an automatized measurement apparatus developed at the University of Zaragoza (Spain) was used. The equipment allowed constant monitoring of absorption, measuring the mass of absorbed water every second, for the whole length of the process. The sample set consisted of six $5 \times 5 \times 5 \mathrm{~cm}$ cubic specimens. The obtained datasets were compared and both the amount of water absorbed by the specimen per unit area $(Q i)$ at a certain time, as well as the capillary water absorption coefficient (AC) were determined. The measurements ended when the difference between two subsequent measures was less than $0.1 \%$ of the whole specimen mass.

\section{Results}

The combination of two complementary porosimetric techniques, MIP (from 0.001 to $75 \mu \mathrm{m}$ ) and HRXCT (from 12 to $200 \mu \mathrm{m}$ ),

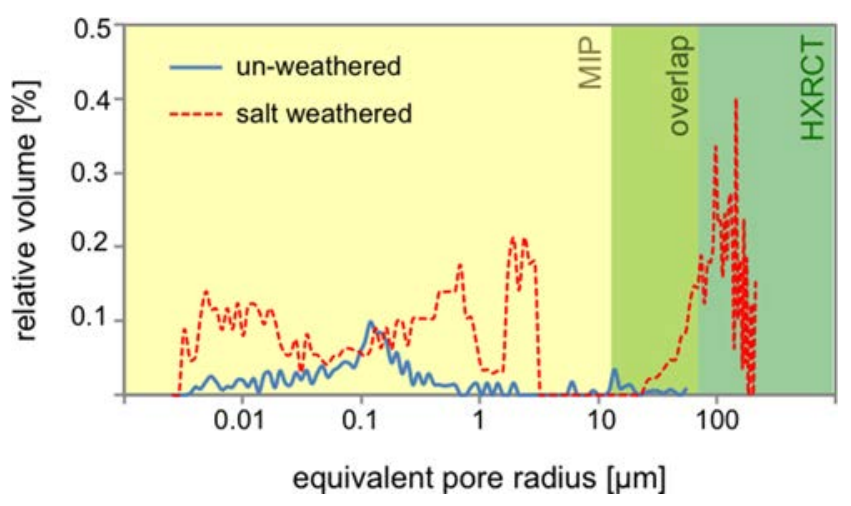

Fig. 3. Macigno sandstone: reconstruction of the whole porosimetric range (combining MIP and HXRCT), comparison between unweathered (blue, solid line) and salt-weathered (red, dashed line) samples (see online version for colour). The total increment of porosity due to decay is associated with the transition from monodisperse to polydisperse distribution 
allows the analysis of the distribution of the access radius of open pores for unweathered and weathered samples (Fig. 3). The unweathered sample shows a monomodal distribution, with a wide peak centred at $0.1 \mu \mathrm{m}$. In contrast, the specimen that underwent salt weathering shows an equidisperse distribution of open pore access radius and an increase in the percentage of pore volume, due to several mechanisms: (i) opening of micro-pores (open pore access radius $<0.1 \mu \mathrm{m}$ ); (ii) widening of the pre-existing porosity up to $1.2 \mu \mathrm{m}$ of access radius; and (iii) the formation of cracks (wide peak centred around $100 \mu \mathrm{m}$ ) (see also Fig. 5). On the whole, MIP also registers an increase in interconnection, in parallel with the decrease in the complementary parameter of tortuosity (Table 1).

The analysis of the hygroscopic performances of the unweathered sample highlights the capability of the structure (i.e. pore network and mineralogical composition) to attract water (Fig. 4a). The comparison with the weathered samples shows that the Macigno sandstone is severely affected by salt crystallization, with a relevant increase in hygroscopic properties, particularly due to the opening of micro-cracks. The joint analysis of MIP and hygroscopic adsorption curves for fresh and salt-weathered samples (Fig. 4b and c) highlights the difference between the two datasets. The discrepancies noticeable for fresh samples in the results acquired with the two different techniques derive from the occurrence of Chl-S mixed-layer clay minerals. These minerals, being hygroscopic, induce an increase in the adsorption activity that is not linked to the actual presence of micropores. It can also be noticed that the MIP technique is likely to be inducing fractures between 0.001 and $0.1 \mu \mathrm{m}$, due to the applied pressure. The curves for the weathered specimens suggest the formation of micro-pores linked to the intra-layer swelling mechanism, represented mainly from microcracks opened inside the phyllosilicates. This observation is corroborated also by the analysis of the pressure/intruded volume plot originated during the MIP test; the generated curves highlight the evolution from intra-granular porosity (fresh sample) to intergranular porosity with decay processes. In fact, in the plot corresponding to the fresh sample, the curve presents a growth followed by a flattening, corresponding to the filling of intergranular voids, and a new growth linked with intra-granular voids; whereas the altered sample presents a constant growth that can be attributed almost entirely to inter-granular voids (Rouquerol et al. 2012). Concurrently, the study of the hysteresis between intrusion and extrusion curves suggests the evolution from cylindrical to platy pores (Fig. 5) (De Boer 1958).

The shape analysis of the pores was also addressed by means of the $3 \mathrm{D}$ reconstruction of the HRXCT scans. Comparison of the scans of the unweathered and weathered samples indicates pores opening as elongated cracks along grain boundaries (Fig. 6), where microscopic observation (Fig. 2) located phyllosilicates.

Petrophysical characterizations were performed to assess more deeply the influence of the fabric on the weathering process. Ultrasound velocity measurements (Table 2) show a relevant decrease in velocity for the direction parallel to the sedimentary horizons, evidencing the presence of discontinuities along these levels and, therefore, suggesting the presence of seismic anisotropies due to the presence of sedimentation planes (Valcke et al. 2006). The salt-weathering treatment produces a consistent decrease in the parallel-direction ultrasound velocity, due to the openings of

Table 1. Macigno sandstone: MIP open porosity and tortuosity values for fresh and salt-altered samples

\begin{tabular}{lcc}
\hline & unweathered & weathered \\
\hline \% open porosity & 1.88 & 6.21 \\
tortuosity & 2.209 & 2.16 \\
\hline
\end{tabular}
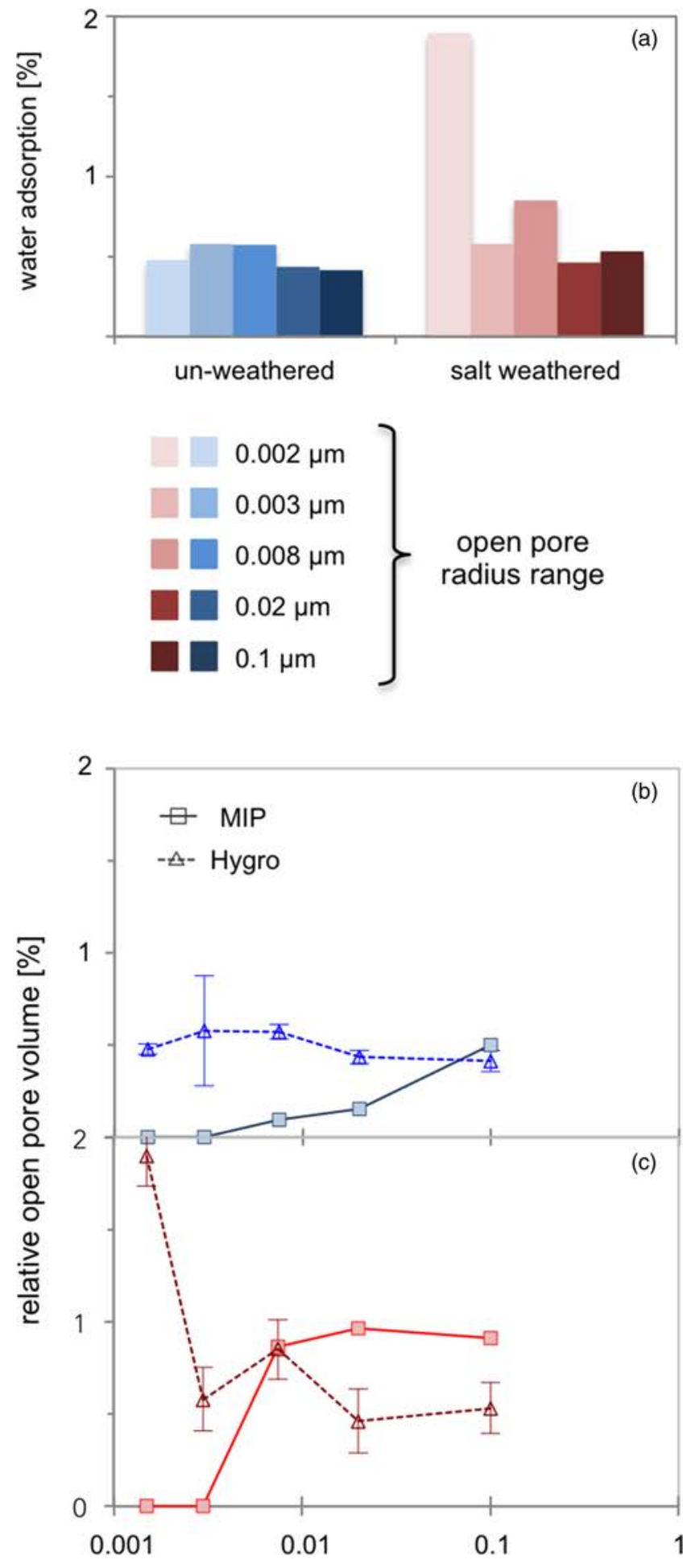

open pore radius $[\mu \mathrm{m}]$

Fig. 4. Macigno sandstone: hygroscopic adsorption behaviour. (a) Comparison between unweathered (blue) and salt-weathered (red) sample (see online version for colour). The increment of adsorbed water is connected to the opening of micro-pores. (b, c) Comparison between MIP and hygroscopic adsorption-based micro-porosimetry; (b) unweathered and (c) salt-weathered samples.

discontinuities along the sedimentary horizons. Also the average anisotropy coefficient is recast. The analysis of the anisotropy coefficient $(K)$ (Table 2) provides a valuable parameter assessing a decrease in the overall quality of the bulk specimen after salt weathering, registered as an increase in anisotropy. 


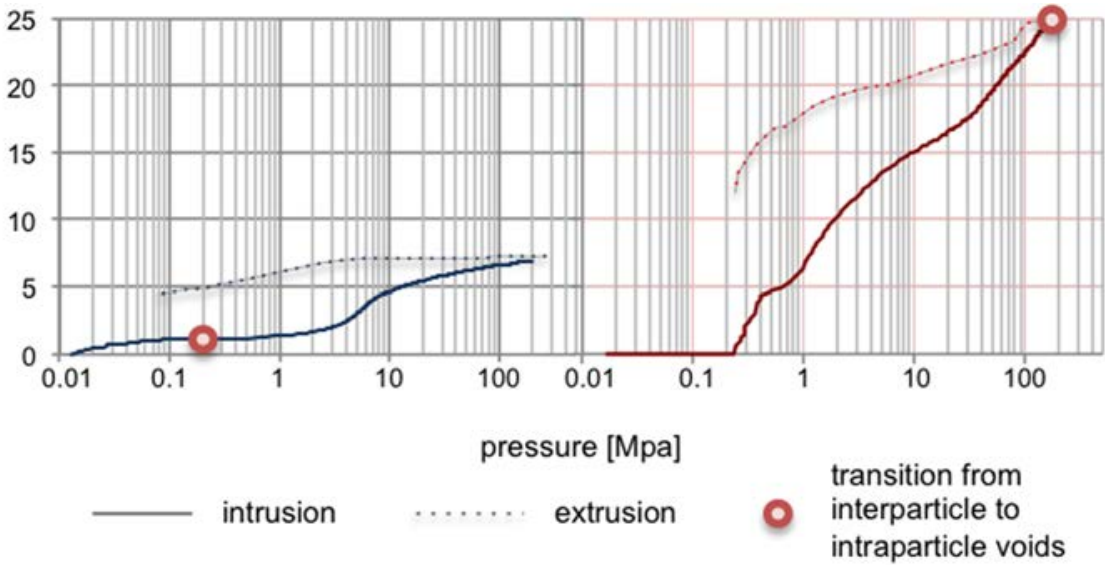

Fig. 5. Macigno sandstone: MIP. Pressureintruded volume plots of the unweathered (blue) and weathered (red) samples (see online version for colour). The comparison highlights the evolution from intra-granular to inter-granular porosity. The hysteresis between the intrusion (solid line) and extrusion (dotted line) curve suggests the evolution from cylindrical to platy pores.
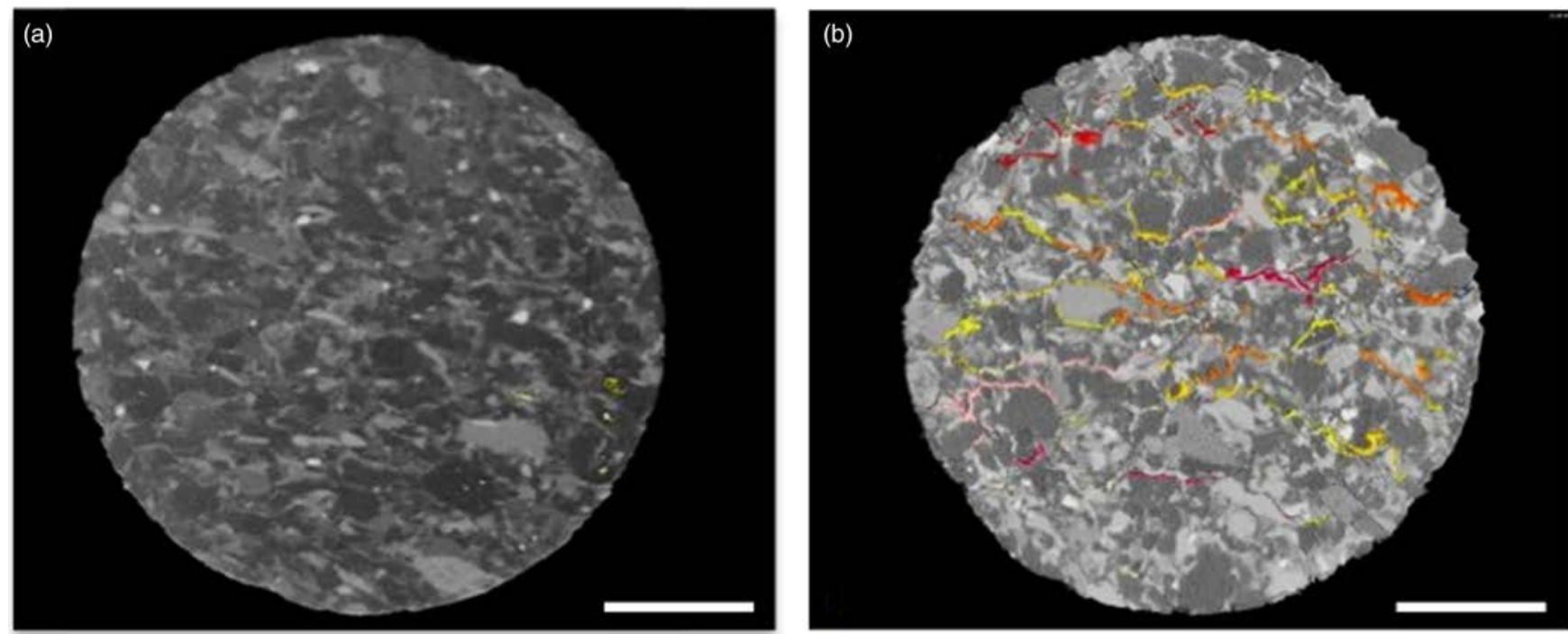

Fig. 6. Macigno sandstone: X-ray computed tomography reconstruction. Scale bar $1 \mathrm{~mm}$. Pores and fracturing are shown in a colour scale from yellow $\left(0^{\circ}\right)$ to red $\left(180^{\circ}\right)$ for increasing radius access (see online version for colour). (a) Unweathered sample: only a few pores can be observed. (b) Salt-weathered sample: the opening of fractures along the structure, especially along grain boundaries and phyllosilicates can be observed.

Ultrasound velocity provided orientation of the apparently homogeneous textures from the quarry. Three oriented, polished sections obtained from one of the samples were examined by SEM image analysis to investigate the extent of preferential orientation of the grains. The rose diagrams (Fig. 7) highlight that the samples were not extracted along the bedding planes. The AC section shows an inclination of the elongated grains of $165^{\circ}$, the $\mathrm{BD}$ section is

Table 2. Macigno sandstone: ultrasound velocities

\begin{tabular}{lccc}
\hline & unweathered & salt-weathered & orientation \\
\hline $\mathrm{v}_{\max }\left(\mathrm{m} \mathrm{s}^{-1}\right)$ & 4656.5 & 4257.8 & EF \\
$\sigma_{\text {st }}\left(\mathrm{m} \mathrm{s}^{-1}\right)$ & 173.1 & 67.6 & \\
$\mathrm{v}_{\min }$ & 3262.7 & 2882 & AC \\
$\sigma_{\text {st }}$ & 122 & 197.6 & \\
$\mathrm{v}_{\text {med }}\left(\mathrm{m} \mathrm{s}^{-1}\right)$ & 4217.9 & 3781.3 & $\mathrm{BD}$ \\
$\sigma_{\mathrm{st}}$ & 52.5 & 80.4 & \\
$K \%$ & 33.02 & 38.5 & \\
$\sigma_{\mathrm{st}}$ & 5.9 & 3.4 & \\
\hline
\end{tabular}

The average values for fresh (5) samples and salt-weathered (before washing - 3) samples are reported along with their standard deviation. The samples that underwent salt weathering were chosen within those analysed to calculate the average values for fresh samples before artificial decay. Also the average anisotropy coefficient $(K)$ for each dataset was recast. characterized by elongated grains with a $90^{\circ}$ angle, while the EF section shows a wider set of orientation from 0 to $45^{\circ}$. On the whole, $3 \mathrm{D}$ reconstruction of the sample allows identifying the sedimentation plane $\mathrm{S}_{0}$. The model (Fig. 7) confirms the ultrasonic measurements, as the values calculated for the $\mathrm{EF}$ and $\mathrm{BD}$ directions are similar (with correct orientation, the ultrasound values of BD should be more similar to those on the AC section, on which lies the $\mathrm{S}_{0}$ plane).

The imperfect orientation of samples compared to the bedding reflects on their capillary uptake properties (Fig. 8a). In fact, in the unweathered sample, only a slight difference, during the first hours, can be observed for the two main orientations. The ultrasoundassumed parallel direction (AC) acted with a faster capillary uptake than the direction supposedly perpendicular to the sedimentary horizons (EF), but, despite the low interconnection, both the directions present a comparable total amount of water at saturation. The method was applied also to the altered samples in order to evaluate the transformation in the water uptake dynamics due to weathering. Only the results for the directions perpendicular to the sedimentary horizon are presented for their relevance (Fig. 8b). The salt-weathered samples after the first hour deviate from the curve of the fresh samples probably due to the enlargement of pore access, seeing an increase in the capillary absorption index to reach a constant value before saturation. 

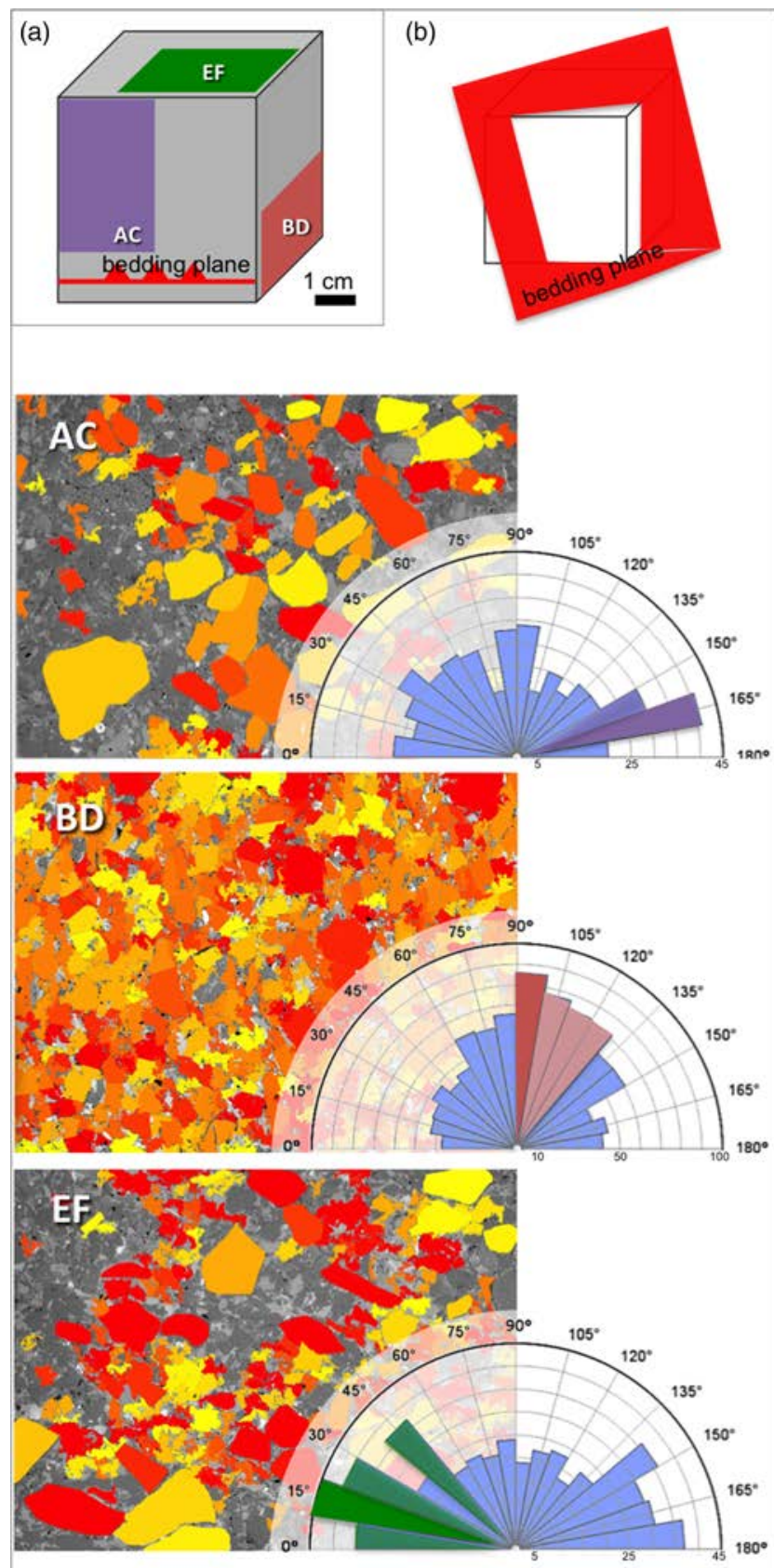

$180^{\circ}$

Fig. 7. Macigno sandstone: image analysis through JMicrovision. The acquired dataset for each oriented section was elaborated through rose diagrams to establish the main clast elongation direction. (a) Scheme of sampling. The orientations were selected after ultrasound measurements along with the supposed bedding plane. (b) Reconstruction model of the real bedding plane, image analysis and rose diagrams obtained by plotting the data acquired for the orientation of the segmented grains, for $\mathrm{AC}, \mathrm{BD}$ and EF.

\section{Discussion}

The analysis of the whole porosimetric interval was achieved by combining MIP, HXRCT and hygroscopic adsorption. Combining the different techniques allows us to mitigate their respective drawbacks and collect a wider porosimetric range (Cnudde et al. 2009). Comparing the porosimetric range with MIP and hygroscopic adsorption permits estimation of the mercury pressureinduced damage (Giesche 2006) to the bulk, and discloses the hygroscopic activity of the rock-forming minerals. Conversely,
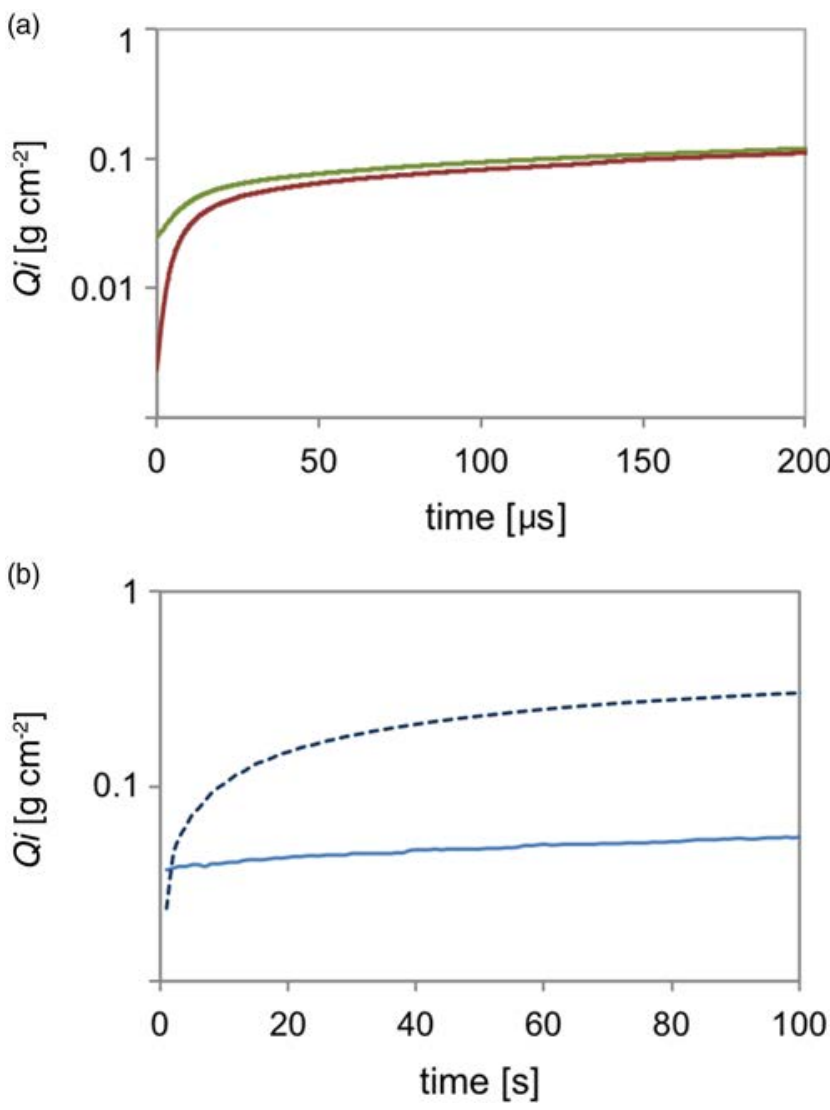

Fig. 8. Macigno sandstone: capillary uptake. (a) Plot of automated measurements on the fresh samples different direction: AC (top, green line), $\mathrm{EF}$ (bottom, red line) (see online version for colour). Along $\mathrm{AC}$ a higher water absorption can be noticed, while EF presents a lower absorption capability. (b) Comparison of the unweathered and weathered dataset collected for the EF orientation. The continuous line represents the fresh samples, for different directions reference while the dashed line indicates the salt-altered measurements. Mechanical decay, with the formation of micro-cracks, induces a higher capillary absorption coefficient.

the overlap of results between MIP and HRXCT matches: (1) the approximations intrinsic of the MIP (Giesche 2006) and (2) the operator dependency and resolution power of HRXCT (Blunt et al. 2013). The analysis of the porosimetric curve trends, associated with the image and petrographic analyses, suggests that during saline weathering the mechanical decay generates cracks. The micro-cracks (radius $<0.1 \mu \mathrm{m}$ ), which cannot be detected by HRXCT analysis due to its limiting resolution, are probably due to the rupture of the Chl-S expansible phyllosilicates along their layers (Sebastián et al. 2008) (Fig. 9), while the major cracks (radius $>10 \mu \mathrm{m}$ ), addressed by HRXCT, are linked with the rupture along grain boundaries and along primary porosity. Moreover, the liability of the clay minerals to attract water induces a high susceptibility to $\mathrm{RH}$ variation (Fig. 9). In fact, in the presence of Chl-S minerals, an increase in humidity in the environment generating swelling is well documented (Benavente et al. 2008; Ruedrich et al. 2011), leading to an increase in volume depending on (i) the modal minerals, (ii) the relative amount of water and (iii) the surrounding environment. Another discriminating factor is the occurrence of micro-pores (i.e. in the unweathered samples the peak of pore access radius centred around $0.1 \mu \mathrm{m}$ - see Fig. 3), being the main water supply for clay minerals inside the bulk rock (Molina et al. 2011; Ruedrich et al. 2011). The analysis of both pore network and mineralogy proved fundamental in uncovering the susceptibility of the lithotype to repeated cycles of adsorption and evaporation that generate swelling/shrinking, which acts as a hydraulic ram, generating 


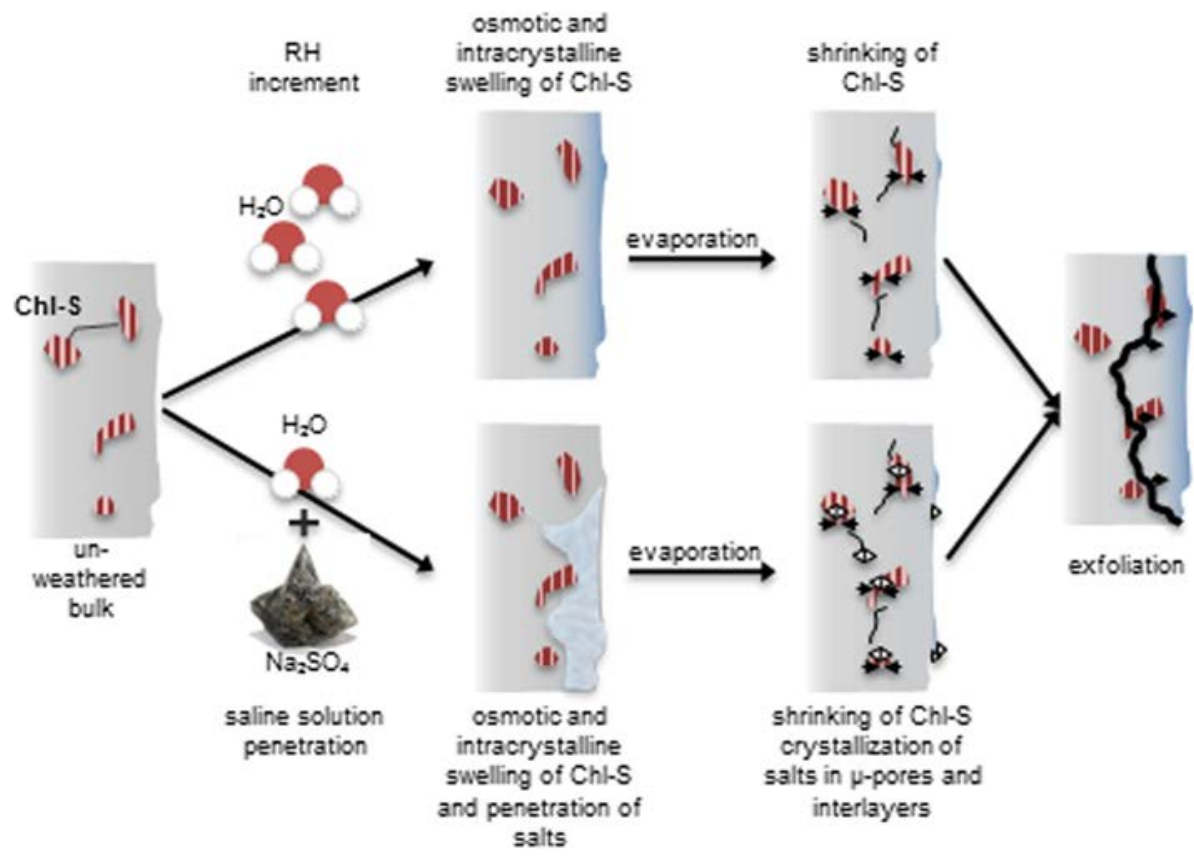

Fig. 9. Macigno sandstone: proposed schematic interpretation of the exfoliation weathering. Not to scale. cracks (Hall \& Hall 1996). All the described mechanisms are consistent with the exfoliation process (Fig. 9) (Veniale et al. 2001).

The characterization of the mineralogical composition of the micro-porous network and the bulk hygroscopic properties is useful in assessing conservation protocols, especially when the environment can be controlled (e.g. statue or architectural ornaments in indoor environments) and intervention can be effective.

Sedimentary features have proven to be crucial for the durability of Macigno sandstone artefacts. Ultrasound tests allowed us to discover the preferential orientations, confirmed through quantitative image analysis. Disclosing the sedimentation planes allows prediction of both the preferential orientation of cracks and the maximum water absorption coefficient. This determination is useful when block replacements are needed in order to expose the surface less subject to weathering.

\section{Concluding remarks}

The analysis of the dataset highlights that the combined action of fabric and mineralogical features can control the decay mechanism of Macigno sandstone and, therefore, the durability of the material, a fact of high relevance when dealing with cultural heritage. This lithotype, in particular, presents an abundance of Chl-S mixed layers, which are subject to swelling-shrinking mechanisms with $\mathrm{RH}$ variation, inducing a high predisposition to deterioration. Moreover, the present work enhances the potential of coupling MIP with hygroscopic adsorption behaviour of rocks when dealing with expandable phyllosilicates and, more generally, micropores.

Acknowledgements We acknowledge the revision of the anonymous referees, who helped us to improve the manuscript. The authors acknowledge Frosini Pietre s.r.l. for providing the samples.

Funding This work was carried out with the financial support of the 'Analisi delle proprietà microstrutturali, chimico-fisiche di materiali inorganici; determinazioni quantitative della composizione mineralogica di materiali naturali e delle proprietà tecniche dei materiali litici' Laboratory funds, DISTAV, University of Genoa. Hannelore Derluyn acknowledges the financial support from the Research Foundation - Flanders (FWO) for her postdoctoral fellowship.

\section{References}

Bastogi, M. \& Fratini, F. 2004. Geologia, litologia, cave e deterioramento delle pietre fiorentine. In: Giusti, A. \& Mariottini, M. (eds) Stones: Ornament of Florence, Special paper, APAT SYSTEMCART, Rome, 27-42.

Benavente, D., García Del Cura, M. a., Bernabéu, A. \& Ordóñez, S. 2001. Quantification of salt weathering in porous stones using an experimental continous partial immersion method. Engineering Geology, 59, 313-325, https://doi.org/10.1016/S0013-7952(01)00020-5

Benavente, D., Cultrone, G. \& Gómez-Heras, M. 2008. The combined influence of mineralogical, hygric and thermal properties on the durability of porous building stones. European Journal of Mineralogy, 20, 673-685, https://doi. org/10.1127/0935-1221/2008/0020-1850

Blunt, M.J., Bijeljic, B. et al. 2013. Pore-scale imaging and modelling. Advances in Water Resources, 51, 197-216, https://doi.org/10.1016/j.advwatres.2012.03.003

Bonini, M., Moratti, G., Sani, F. \& Balestrieri, M.L. 2013. Compression-toextension record in the late Pliocene-Pleistocene Upper Valdarno Basin (Northern Apennines, Italy): Structural and thermochronological constraints. Italian Journal of Geosciences, 132, 54-80, https://doi.org/10.3301/IJG.2011.18

Brabant, L., Vlassenbroeck, J., De Witte, Y., Cnudde, V., Boone, M., Dewanckele, J. \& Van Hoorebeke, L. 2011. Three-dimensional analysis of high-resolution X-ray computed tomography data with Morpho+. Microscopy and Microanalysis, 17, 252-263, https://doi.org/10.1017/S1431927610094389

Cnudde, V. \& Boone, M.N. 2013. High-resolution X-ray computed tomography in geosciences: A review of the current technology and applications. EarthScience Reviews, 123, 1-17, https://doi.org/10.1016/j.earscirev.2013.04.003

Cnudde, V., Cwirzen, A., Masschaele, B. \& Jacobs, P.J.S. 2009. Porosity and microstructure characterization of building stones and concretes. Engineering Geology, 103, 76-83, https://doi.org/10.1016/j.enggeo.2008.06.014

De Boer, J.H. 1958. The shapes of capillaries. In: Everett, D.H. \& Stone, F.S. (eds) The Structure and Properties of Porous Materials. Butterworths, London, 68-94

Delgado Rodrigues, J. 2001. Evaluación del comportamiento expansivo de las rocas y su interés en conservación. Materiales De Construcción, 51, 183-195, https://doi.org/10.3989/mc.2001.v51.i263-264.363

Falorni, P. 2007. Macigno. Carta Geologica D'Italia 1:50.000 - Catalogo Delle Formazioni, Rome, 281-289.

Giesche, H. 2006. Mercury porosimetry: A general (practical) overview. Particle and Particle Systems Characterization, 23, 9-19, https://doi.org/10.1002/ ppsc. 200601009

Gioncada, A., Leoni, L., Lezzerini, M. \& Miriello, D. 2011. Relationships between mineralogical and textural factors in respect to hydric dilatation of some sandstones and meta-sandstones from the Northern Apennine. Italian Journal of Geosciences, 130, 394-403, https://doi.org/10.3301/IJG.2011.16

Hall, K. \& Hall, A. 1996. Weathering by wetting and drying: some experimental results. Earth Surface Processes and Landforms, 21, 365-376, https://doi.org/ 10.1002/(SICI)1096-9837(199604)21:4 \&lt; 365::AID-ESP571 > 3.0.CO;2-L

ICOMOS \& ISCS 2008. Illustrated Glossary on Stone Deterioration Patterns, ICOMOS, Paris.

Leoni, L., Lezzerini, M., Battaglia, S. \& Cavalcante, F. 2010. Corrensite and chlorite-rich Chl-S mixed layers in sandstones from the 'Macigno' Formation (northwestern Tuscany, Italy). Clay Minerals, 45, 87-106, https://doi.org/10. 1180/claymin.2010.045.1.87

Madsen, F. \& Mueller Vonmoos, M. 1989. The swelling behaviour of clays. Applied Clay Science, 4, 143-156. 
Masschaele, B., Dierick, M. et al. 2013. HECTOR: A 240kV micro-CT setup optimized for research. Journal of Physics: Conference Series, 463, 12012, https://doi.org/10.1088/1742-6596/463/1/012012

Milne, I.H. \& Warhaw, C.M. 1955. Methods of preparation and control of clay mineral specimens in X-ray diffraction analysis. Clays and Clay Minerals, $\mathbf{4}$, 22-30, https://doi.org/10.1346/CCMN.1955.0040104

Molina, E., Cultrone, G., Sebastián, E., Alonso, F.J., Carrizo, L., Gisbert, J. \& Buj, O. 2011. The pore system of sedimentary rocks as a key factor in the durability of building materials. Engineering Geology, 118, 110-121, https:// doi.org/10.1016/j.enggeo.2011.01.008

Pecchioni, E., Vettori, S., Cantisani, E., Fratini, F., Ricci, M. \& Garzoio, C. 2016 Chemical and mineralogical studies of the red chromatic alteration of Florentine Pietra Serena sandstone. European Journal of Mineralogy, 28, 449-458.

Roduit, N. 2007. JMicroVision: Un logiciel d'analyse d'images pétrographiques polyvalent. $\mathrm{PhD}$ thesis, University of Geneve, France.

Rouquerol, J., Baron, G. et al. 2012. Liquid intrusion and alternative methods for the characterization of macroporous materials (IUPAC Technical Report). Pure and Applied Chemistry, 84, 107-136, https://doi.org/10.1351/pac-rep10-11-19
Ruedrich, J., Bartelsen, T., Dohrmann, R. \& Siegesmund, S. 2011. Moisture expansion as a deterioration factor for sandstone used in buildings. Environmental Earth Sciences, 63, 1545-1564, https://doi.org/10.1007/ s12665-010-0767-0

Sebastián, E., Cultrone, G., Benavente, D., Linares Fernandez, L., Elert, K. \& Rodriguez-Navarro, C. 2008. Swelling damage in clay-rich sandstones used in the church of San Mateo in Tarifa (Spain). Journal of Cultural Heritage, 9, 66-76, https://doi.org/10.1016/j.culher.2007.09.002

Valcke, S.L.A., Casey, M., Lloyd, G.E., Kendall, J.M. \& Fisher, Q.J. 2006 Lattice preferred orientation and seismic anisotropy in sedimentary rocks. Geophysical Journal International, 166, 652-666, https://doi.org/10.1111/j. 1365-246X.2006.02987.x

Veniale, F., Setti, M., Rodriguez-Navarro, C. \& Lodola, S. 2001. Role of clay constituents in stone decay processes. Materiales de Construccion (Madrid, Spain), 51, 163-182.

Vlassenbroeck, J., Dierick, M., Masschaele, B., Cnudde, V., Van Hoorebeke, L. \& Jacobs, P. 2007. Software tools for quantification of X-ray microtomography at the UGCT. Nuclear Instruments and Methods in Physics Research, Section A: Accelerators, Spectrometers, Detectors and Associated Equipment, 580, 442-445, https://doi.org/10.1016/j.nima.2007.05.073 